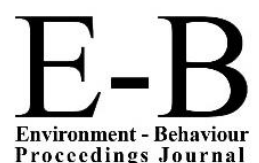

Environment - Behaviour
Procecdings Journal

\section{CSSR 2017}

https://www.amerabra.org; https://fspu.uitm.edu.my/cebs; https://www.emasemasresources.com

$4^{\text {th }}$ International Conference on Science \& Social Research

The Pines, Malacca, Malaysia, 06 -07 December 2017

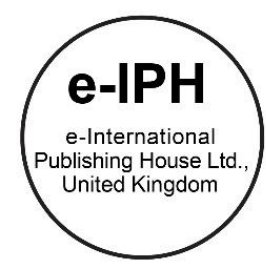

\title{
User Specifications for Successful New Product: A case study in car design
}

\author{
Hassan Alli ${ }^{1}$, Mohd Amil Faesal Fauzi ${ }^{2}$ \\ Department of Industrial Design, Faculty of Design and Architecture, \\ University Putra Malaysia, Serdang, Selangor, Malaysia \\ halli@upm.edu.my1', amilfaesal@gmail.com² \\ Tel: +60122761002
}

\begin{abstract}
The ability to develop a new successful product is the main concern of many product developers. Understanding the user requirements and preferences are challenging for a product designer. This paper aims to investigate the user specifications for successful a new product. A case study is conducted to identify the user specification that influenced the success of car design. Both the experience designers and end-users were found to agree on the expectation. The result is used to establish the new product characteristics and assistance the product designer in the product development and increase the probability of product success.
\end{abstract}

Keywords: New product development, user specification, product success and car design

eISSN: 2398-4287 @ 2020. The Authors. Published for AMER ABRA cE-Bs by e-International Publishing House, Ltd., UK. This is an open access article under the CC BYNC-ND license (http://creativecommons.org/licenses/by-nc-nd/4.0). Peer-review under responsibility of AMER (Association of Malaysian Environment-Behaviour Researchers), ABRA (Association of Behavioural Researchers on Asians) and cE-Bs (Centre for Environment-Behaviour Studies), Faculty of Architecture, Planning \& Surveying, Universiti Teknologi MARA, Malaysia.

DOI: https://doi.org/10.21834/ebpj.v5iSI1.2311

\subsection{Introduction}

New product development is often defined as a process to produce a new physical product accompanied by its purpose or function while considering the aesthetic elements. The development of a new product is a sequence of activities that enterprise employs to conceive, design, and commercialize a product through intellectual and organizational involvement (Krishnan \& Ulrich, 2001; Ottosson, 2006; Isaksson, et al., 2011). It attempts to produce a product design specification and physical form based on the needs, wants and wishes of the user, and bring new technology into a product that is available for sale. Latterly, a new product plays an important role to enhance the business value of a company. The introduction of new products has increased dramatically as the industry becomes more responsive to the importance of the new product to business competitiveness (Bhuiyan, 2011; Taha, et al., 2013; Alli 2018). However, the nonacceptance of a new product in the market continues to become a major concern for many product developers. Many factors were influenced for better product outcome and its success in the market. Several researchers have revealed that the implementation of a new strategy for a new product in the industry encountered difficulties in facilitating product positioning in the market (Kristensson, et al., 2007; Awa, 2010; Taha, et al., 2013; Alli, 2018). The strategies are mostly required in the early stage of the product development process to enhance the quality of the product, meet the user satisfaction and increase the probability of its success. The initial stage of the development process is called the product definition stage. It is crucial step in the design process through which the particulars gained from the market information and useful knowledge such as their want, need and requirement is translated into product specifications (Taha, et al., 2013; Alli, 2014; Alli, 2018). The concept of the product definition stage implies the activities from the mission statement to the development plan.

eISSN: 2398-4287 @ 2020. The Authors. Published for AMER ABRA cE-Bs by e-International Publishing House, Ltd., UK. This is an open access article under the CC BYNC-ND license (http://creativecommons.org/licenses/by-nc-nd/4.0/). Peer-review under responsibility of AMER (Association of Malaysian Environment-Behaviour Researchers), ABRA (Association of Behavioural Researchers on Asians) and cE-Bs (Centre for Environment-Behaviour Studies), Faculty of Architecture, Planning \& Surveying, Universiti Teknologi MARA, Malaysia. DOI: https://doi.org/10.21834/ebpj.v5iSI1.2311 
Involving the user in product development is the most efficient method in helping the product designer to gather information pertaining to their requirements and preferences. However, there are no specific reference clearly stating the accurateness about user knowledge concerning their requirement and preference for product design that can facilitate the product developers to incorporate them into the development of a new product. A better understanding of the user need a systematic process for identifying their requirements and should be done in the first stage of the design process. As a result, many product designers are disappointed that they do not have equivalent information support in the early stage of product development process. It is thus, the purpose of this paper is to provide an in-depth understanding of user specification that contribute to the successful a new product.

\subsection{Literature Review}

In recent years, the user has an essential role in the development of a new product, mainly in determining the product characteristics by offering their perspectives. The user perspective is a personal point of view. It becomes information and can help the product designer to generate new product feature, and an effective in finding a solution to a complex problem (Kujala, 2003; Ottosson, 2006; Taha, et al., 2013; Alli, 2018). To some extent, the ability of product developer to extract and integrate user knowledge during the development of a product design process is considered as a good design strategy, could be one of a company's competencies, could provide considerable to innovative idea, and could offer more opportunities and producing the success of a new product. Consequently, the users have become the resources for bringing new technology, market information and supporting the development capabilities of the manufacturer and facilitate the product developers to generate more ideas and create a new outlook of product quality. According to Awa (2010); Taha, et al., (2013); Alli (2018), understanding the user can increase the productivity, quality of work and minimize support, operating cost, and improved user satisfaction. Indeed, the user is necessary to identify are and establish the new product characteristics that meet their requirements. The collaborating with the user during the new product development process will also provide a clearer picture of the intended product that is to be produced (Taha, et al., 2013; Alli, 2018). However, understanding the user information has been recognized as a pressing challenge for the product developer. The quality and type of information needed from the user are also challenging to determine. As a result, the product developer may make mistakes or misjudgments in several aspects of product design. A study by Light Mind Ltd. (2005) suggested that there are three key elements to understand the use when developing a new product: 1) desirability - the new product must satisfy the person wanting to use it or meet user requirements, 2) purpose - the product must have useful functions, and 3) user experience - the product must provide user satisfaction. However, desirability is regarded as a fundamental element for achieving an outcome that will subsequently be positively perceived and become successful in the market (Warell, et al., 2006; Taha, et al., 2013; Alli, 2014; Alli, 2018).

A product will become successful if the product developers have compressive information and data concerning user requirements. It is more successful if the new product can bring high performance, gives a significant benefit and is more dominant compared to other products. However, the failure of a new product is feared by most product developers and has made the product development process the most challenging task. According to Awa (2010), many product developers are unable to develop an innovative product because of their failure to minimize the failure's risk and maximize product values. The success of a product not only attracts more attention and provides more value in the market, but it also signifies the success of the product developers in expressing a comprehensive vision of the product user needs (Gonzalez \& Palacious, 2002; Kristensson, et al. 2007; Alli, 2014). Besides, it is also dependent on the product development process in terms of implementation and completeness. Many factors influence a better product outcome, such as cost, quality, delivery, dependability, innovation and flexibility variations of demand. From the perspective, several researchers state that the success of a new product can be analyzed from four different viewpoints such as a design that fulfils the technical requirements, increase the return on investment, delivers high performance, and fulfils user needs. While, the product designer state that the success of a product depends on the acceptance of a user for a variety of reasons, some of which are technical and some non-technical. Thus, involving the user during the product development process is significant and is often required by product developers to develop the product design specification. Also, the product developers are agreed that a new product should purposely design and works according to its objective. It also requires a product established innovatively with its detail prescription and fulfil the user's expectation.

The product developers have become more aware of the need to be more responsive to user specification attempt to minimize the risk of product irrelevance, reduce the development time and increase better product design outcome. The early stage of the design process is the most efficient phase to incorporate user into new product development. The specification is valuable to establish the characteristics of a new product. Besides, this also highly contributes to the level of unique design and performance of a new product. Every product is built on many variable features or known as specification, which becomes its personal and individual character. The variables are often referring to safety and well-being, functionality, usability and the pleasure of the user (Bonapac, 2002). Also, product cost, performance, safety, reliability, efficiency, security, user-friendliness, operability, comfort, style and convenience (Taha, et al., 2013; Alli, 2014). The variables were frequently used in design process mainly to guide the product designers to develop a new product attributes. The elements of product design specification can be divided into physical and non-physical characteristics. Product designers are responsible for selecting appropriate specifications for their products by considering these. Several authors however have distinguished specification elements into demand and wishes of the users (Taha, et al., 2013; Ulrich \& Eppinger, 2016; Alli 2018), however, is not clearly identified, the specific elements that are contributing to the success of a new product and what users really want and need, have not been clearly documented. 


\subsection{Methodology}

To obtain the user specifications that can increase the probability of success of a new product, a case study was conducted involved with experience designers and end-users. The questions seek to identify the user specifications that influenced the success of car design. The PERODUA MyVi was selected as the subject of this study based on its sales reputation in the Malaysia market. This car was unbeaten and ranked highest in the compact car segment in 2009 with a total sale of 378,000 units, and was awarded the prestigious best model 2010 from the Frost \& Sullivan Asian Automotive. Structured interviews were conducted with five (5) respondents, who have more than six years' experience in car design and development, and were directly involved in the PERODUA MyVi project. Questionnaires were also distributed to sixty (60) PERODUA car user owners who have experience with strategic selection decision. The quantitate data was used to gain an in-depth understanding of the proposed investigation. The data from empirical is analyzed using SPSS software.

\subsection{Findings}

\section{a) Experience Designers}

The five respondents selected as participants in this survey consisted of a design manager, a chief designer, a specialist, chief designer and two senior designers. Three of the respondents have 6-10 years' experience in product development, while the other two respondents have more than eleven years' experience. Product developers believe that user provides many opportunities to enhance ideas and value, improve the quality of the product, accelerates product development and reduces development cost.

Table 1: User in Car Development

\begin{tabular}{lllllll}
\hline User in car development & $\mathrm{N}$ & Median & Mode & Min & Max & Sum \\
\hline $\begin{array}{l}\text { B1. The importance user in } \\
\text { car design }\end{array}$ & 5 & 5.00 & 5.00 & 4.00 & 5.00 & 23.0 \\
\hline $\begin{array}{l}\text { B2. User-contributed to success } \\
\text { of car design }\end{array}$ & 5 & 5.00 & 5.00 & 4.00 & 5.00 & 23.0 \\
\hline
\end{tabular}

Table 1 shows the user in car development. The result indicated that the respondents strongly recognized the importance of the user and their contribution to the success of car design. The respondents also stated that the user has a positive impact on the effectiveness of a new product and increases the value of the product through information sharing between them.

Table 2: Factors Influencing the Success in Car Design

\begin{tabular}{lllllll}
\hline Success Factor & N & Median & Mode & Min & Max & Sum \\
\hline Good Design & 5 & 5.00 & 5.00 & 4.00 & 5.00 & 23.00 \\
Multi-Function & 5 & 4.00 & 4.00 & 4.00 & 5.00 & 21.00 \\
Advanced Technology & 5 & 3.00 & 3.00 & 3.00 & 4.00 & 17.00 \\
Good Brand & 5 & 4.00 & 4.00 & 3.00 & 4.00 & 19.00 \\
User Friendly & 5 & 5.00 & 5.00 & 4.00 & 5.00 & 23.00 \\
Environmentally Friendly & 5 & 4.00 & 4.00 & 4.00 & 5.00 & 22.00 \\
Good Performance & 5 & 4.00 & 4.00 & 4.00 & 5.00 & 22.00 \\
\hline
\end{tabular}

Table 2 shows the factors influencing the success in car design. The result indicated that most of the respondents identified that excellent design and user-friendly as significant contributor to the success of car design followed by excellent performance and environmentally friendly, multi-function, good brand, and advanced technology.

\section{b) End-Users}

Two different groups were identified from the car users, namely the primary and secondary car users. 66.7 per cent of the respondents were identified as the primary user, while 33.3 per cent of the respondents are classified as a secondary user. The primary user is recognized as a person who uses the car as their first car, whereas the secondary user is a person who uses the car, but not as a first car. There are three foremost preferences in the buying decision of a new car which are design, price and brand. Fig. 1 shows the user buying decision of a new car. The results indicated that design ( 55.0 per cent) is highly preferred by the user, followed by price ( 35.0 per cent) and brand (10.0 per cent).

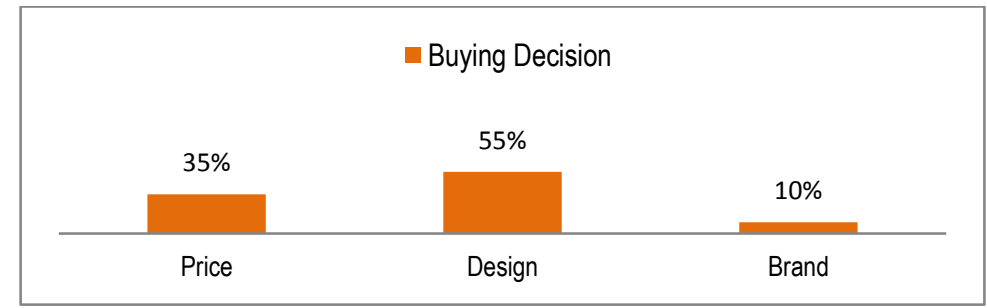

Fig.1: User Buying Decision for a New Car 
Table 3 shows the factors influencing car selection. The results indicated that easy to operate is the highest priority when selecting by end-users, followed by simple \& compact, aesthetical design, user-friendly, contemporary style and driving performance, driving comfort, technology, environmentally friendly, own identity, image, and safety.

Table 3: Factors Influencing Car Selection

\begin{tabular}{lcccccc}
\hline Car Selection Decision & $\mathrm{N}$ & Median & Mode & Min & Max & Sum \\
\hline Easy to Operate & 60 & 4.00 & 4.00 & 2.00 & 5.00 & 251.00 \\
Simple \& Compact & 60 & 4.00 & 4.00 & 1.00 & 5.00 & 250.00 \\
Aesthetical Design & 60 & 4.00 & 4.00 & 1.00 & 5.00 & 235.00 \\
User-friendly & 60 & 4.00 & 4.00 & 1.00 & 5.00 & 231.00 \\
Contemporary Style & 60 & 4.00 & 4.00 & 1.00 & 5.00 & 230.00 \\
Driving Performance & 60 & 4.00 & 4.00 & 1.00 & 5.00 & 230.00 \\
Driving Comfort & 60 & 4.00 & 4.00 & 1.00 & 5.00 & 227.00 \\
Technology & 60 & 4.00 & 4.00 & 1.00 & 5.00 & 224.00 \\
Environmentally Friendly & 60 & 4.00 & 4.00 & 1.00 & 5.00 & 218.00 \\
Own Identity & 60 & 4.00 & 4.00 & 1.00 & 5.00 & 217.00 \\
Image & 60 & 4.00 & 3.00 & 1.00 & 5.00 & 216.00 \\
Safety & 60 & 4.00 & 4.00 & 1.00 & 5.00 & 214.00 \\
\hline
\end{tabular}

Table 4 shows five critical selection decisions for car design. The results indicate that easy to use (90 per cent) is the top priority selection by the primary user of the car, followed by aesthetical design, simple \& compact, user-friendly (83.3 per cent), and contemporary style ( 80 per cent). The secondary user of the car stated that simple \& compact (80 per cent) is the highest priority for selection, followed by easy to use (76.7 per cent), contemporary style (66.7 per cent), aesthetical design (66.6 per cent), and user friendly (53.3 per cent).

Table 4: Five Crucial Selection Decision for the Car Design

\begin{tabular}{|c|c|c|c|c|c|c|c|}
\hline \multirow{2}{*}{$\begin{array}{l}\text { Selection } \\
\text { Decision }\end{array}$} & \multirow{2}{*}{ User } & \multicolumn{5}{|c|}{ Categorical Scale } & \multirow[b]{2}{*}{ Total } \\
\hline & & 1 & 2 & 3 & 4 & 5 & \\
\hline Easy to & Primary & & $3.3 \%$ & $6.7 \%$ & $43.3 \%$ & $46.7 \%$ & $100.0 \%$ \\
\hline Operate & Secondary & & & $23.3 \%$ & $50.0 \%$ & $26.7 \%$ & $100.0 \%$ \\
\hline \multirow[t]{2}{*}{ Simple \& Compact } & Primary & & $3.3 \%$ & $13.3 \%$ & $40.0 \%$ & $43.3 \%$ & $100.0 \%$ \\
\hline & Secondary & & & $20.0 \%$ & $50.0 \%$ & $30.0 \%$ & $100.0 \%$ \\
\hline \multirow[t]{2}{*}{ Aesthetical Design } & Primary & & $3.3 \%$ & $10.0 \%$ & $56.7 \%$ & $30.0 \%$ & $100.0 \%$ \\
\hline & Secondary & $3.3 \%$ & $3.3 \%$ & $26.7 \%$ & $53.3 \%$ & $13.3 \%$ & $100.0 \%$ \\
\hline Contemporary & Primary & & $6.7 \%$ & $13.3 \%$ & $60.0 \%$ & $20.0 \%$ & $100.0 \%$ \\
\hline Style & Secondary & $3.3 \%$ & $6.7 \%$ & $23.3 \%$ & $46.7 \%$ & $20.0 \%$ & $100.0 \%$ \\
\hline User & Primary & & & $16.7 \%$ & $50.0 \%$ & $33.3 \%$ & $100.0 \%$ \\
\hline Friendly & Secondary & $3.3 \%$ & $6.7 \%$ & $36.7 \%$ & $40.0 \%$ & $13.3 \%$ & $100.0 \%$ \\
\hline
\end{tabular}

Fig. 2 shows elements contributed to the success of car design. The results indicate that usability (86.7 per cent) is identified as the main element of the success of a car design followed by technology and form (83.3 per cent), appearance, performance, quality and maintenance (81.7 per cent), shape (80.0 per cent), reliability (79.0 per cent), durability (76.0 per cent) effectiveness, ergonomic and size (75.0 per cent), lifetime, identity and style (71.7 per cent), component and safety (70.0 per cent), image (68.3 per cent), color (65.0 per cent), brand (64.0 per cent), material (58.3 per cent), interface (51.7 per cent), and texture ( 46.6 per cent).

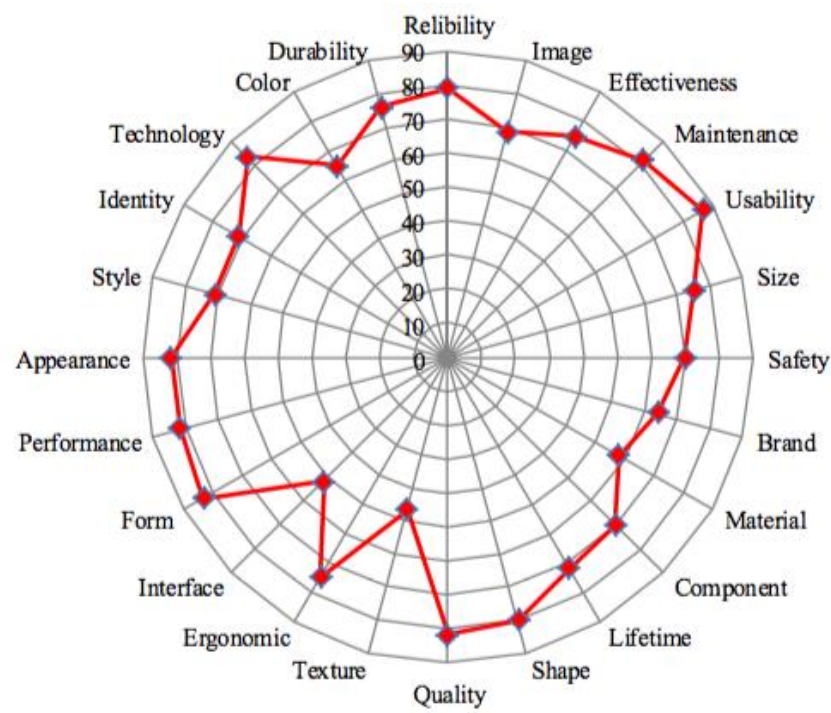

Fig.2: Elements Contributed to the Success of Car Design 


\subsection{Discussion}

User contribution in product development has been widely recognized as a key contributor in the success of a product. Their contribution is not only meant to support the product design development but also provides better information for the establishment of product characteristics. In this empirical study, it has become more essential for the user to be involved during the early stage of the design process, known as product definition, where all information about the product is analyzed and concluded before the design concept begins. This study has also shown that product developers highly recommended the user in the design process as it can help them generate new ideas and prevent the irrelevant creation product, as well as producing high quality. It is widely known that user acceptability and satisfaction are key performance indicators in determining the success of a new product.

The empirical investigation has identified five selection decision of car design (PERODUA MyVi). Primary car users placed priority on easy to operate as their priority selection of car design, while the secondary user prefers simple \& compact. While, it was also found that there are twenty-four elements as user specifications for a successful product (see Fig. 2). Three highest priorities in the success of car design (PERODUA MyVi) are identified; 1) usability, 2) technology and form, and 3) appearance, performance, quality and maintenance. User contribution in product development has become a factor that has a huge impact on the success of a new product. The user specifications are valuable in providing product information for establishing the characteristics of a new product. They can facilitate product developer to generate better innovative ideas and provide more opportunities for product success. The elements of product design are a collection of product requirements and are also known as the product design specification. The product design specification provides a categorization scheme for product requirements that make every product requirements in a specification belong to one requirements group, which is always considered during the design stage.

\subsection{Conclusion and Recommendations}

User involvement is highly required in the new product develop (NPD) process. They can help the product designer to generate new product idea, prevent creating irrelevant product, and produce the highest product quality. The user is also valuable as a source of product information for product knowledge. The information is important to identify the product specification in order to establish the characteristics of a new product. Furthermore, the information from the user will also help the product developers to optimize design decision and minimize the product failure.

\section{Acknowledgments}

The authors gratefully acknowledge the help of the Research Management Centre (RMC), University Putra Malaysia for their helpful support and providing the grant (Grant no. 9526400). The authors also wish to express appreciation and gratitude to everyone who has been involved and contributed knowledge, idea and experience as product designer and respondents in this study.

\section{References}

Alli, H. (2018). User involvement method in the early stage of new product development process for successful product. ALAM CIPTA: International Journal of Sustainable Tropical Design Research and Practice, 11(1), 23-28.

Alli, H. (2018). Evaluation theories of product definition method for successful anew product. ALAM CIPTA: International Journal of Sustainable Tropical Design Research and Practice, 11(2), 52-56.

Alli, H. (2014). The process in developing a new successful product. In Sustainable Tropical Environmental Design Exhibition (STEdex'14). 6, $248-253$.

Awa, H. O. (2010). Democratizing the new product development process: A new dimension of value creation and market concept. International Business Research, 3(2), 49-59.

Binnur, A-K. (2002). Innovation management in multi-divisional firm: Factors that lead to successful development of new product. National Technological University.

Bhuiyan, N. (2011). A framework for successful new product development. Journal of Industrial Engineering and Management, 4(4), 746-770.

Bonapace, L. (2002). Linking Product Properties to Pleasure: Sensorial Quality Assessment Method (SEQUAM). In P. W. Jordan \& W. S. Green (Eds.), Pleasure with products: Beyond usability (pp. 189-218). London: Taylor \& Francis

González, F. J. M., \& Palacios, T. M. B. (2002). The effect of new product development techniques on new product success in Spanish firms. Industrial Marketing Management, 31(3), 261-271.

Isaksson, O., Larson, T. C., \& Johansson, P. (2011). Towards a framework for developing product/ service system. Braunschweing: $3^{\text {rd }}$ CIRP International Conference on Industrial Product Service System.

Heiskanen, E., \& Repo, P. (2007). User involvement and entrepreneurial action. Human Technology, 3(2), 167-187.

Krishnan, V., \& Ulrich, K. T. (2001) Product development decision: A review of literature. Management Science, 47(1), 1-21.

Kristensson, P., Matthing J., \& Johansson, N. (2007). Key strategies for the successful involvement of customer in the co-creation of new technology-based services. International Journal of Service Industry Management, 19(4), 474-491 
Alli, H., \& Faesal Fauzi, M.A./ CSSR2017, $4^{\text {th }}$ International Conference on Science \& Social Research The Pines, Malacca, Malaysia, 06 -07 December 2017/ E-BPJ, 5(S11), Jun 2020 (pp.137-142)

Kujala, S. (2003). User involvement: A review of the benefit and challenge. Behavior and Information Technology, 22(1), 1-16.

Light Mind Ltd. (2005). Understanding customer need during new product development: The application of ethnography. www.lighminds.co.uk

Ottosson, S. (2006). Handbook in innovation management - Dynamic business and product development. Review of Marketing Research, 6, 84-106.

Taha, Z., Alli, H., \& Abdul-Rashid, S. H. (2013). The characteristics of a new product through user knowledge in the early stages of a design process. Journal of Advanced Materials Research, 739, 678-683.

Warell, A. (2001). Design syntactic: A functional approach to visual product form-theory, model and method. PhD Thesis: Chalmers University of Technology, Gothenburg.

Wieringa, R. J. (2006). Requirements engineering: Framework for understanding. PhD Thesis: Vrije Universiteit, Amsterdem.

Ulrich, K. T., \& Eppinger, S. D. (2016). Product design and development (6th eds.). New York: McGraw Hill 